\title{
Post-operative surgical site infection among general surgery patients: Rate and risk factors.
}

\begin{abstract}
Shahid Nazir Memon', Shehzada Ameer Ahmed Babar², Sarwat Sultana ${ }^{3}$, Sulhera Khan ${ }^{4}$, Amir Hussain Khan ${ }^{5}$, Anas Bin Tariq ${ }^{6}$

1. MBBS

Medical Officer Surgery

Liaquat University of Medical Health Sciences

(LUMHS) Jamshoro.

2. MBBS, FCPS

Assistant Professor Surgery

Bolan University of Medical and

Health Sciences Quetta.

3. MBBS, MCPS Community Medicine

and MCPS Gynecology

Assistant Professor Community

Medicine in Karachi Medical and

Dental College

4. MBBS

P.G. year 1, General medicine, Jinnah Postgraduate Medical Center

5. MBBS

House Officer, Pediatrics, Ruth K M

Pfau Civil Hospital Karachi

6. MBBS

Resident Medical Officer

Naz Memorial Hospital.

ABSTRACT... Objectives: High rate of post-surgical infections are reported with scanty effort for controlling them. The objectives were to evaluate frequency of surgical site infections in patients undergoing general surgery. Study Design: Cross Sectional Observational Study. Setting: Naz Memorial Hospital. Period: March 2019 to March 2020. Material \& Methods: This study was conducted in general surgery ward for 1 year. All patients over 18 years admitted in surgery ward either as elective or emergency case were included while patients having any wound infection, operated in other hospital or diabetic foot and all those operated for incision and drainage of abscess were excluded. All patients that were operated during the study period were followed for any wound infection development till one qAqmonth. SPSS was used for data entry and analysis keeping p-value of $<0.05$ as significant. Results: 75 from 200 patients developed surgical site infection, 46 (61.3\%) were operated in emergency. Among 24 contaminated surgeries type, $70.8 \%$ were reported having SSI (p-0.05) while from 28 dirty types of surgeries $78.6 \%$ of patients had a SSI (p-0.03). $25 \%$ were anemic, $21 \%$ diabetic while $(20 \%)$ were reported to be hypertensive, 13 (17\%) gave positive history of smoking while $12(16 \%)$ were obese. Conclusion: Higher proportion of surgical site infection was observed in patients undergoing contaminated and dirty type of surgeries. Most patients with SSI were operated in emergency setting and anemia and diabetes were the most common risk factor reported in the infected patients.
\end{abstract}

Correspondence Address:

Dr. Anas Bin Tariq

Naz Memorial Hospital

anastariq93@gmail.com

Article received on:

12/09/2020

Accepted for publication:

$24 / 11 / 2020$

Key words: $\quad$ Post-operative Care, Surgical Site Infection, Type of Surgery.

Article Citation: Memon SN, Babar SAA, Sultana S, Khan S, Khan AH, Tariq AB. Postoperative surgical site infection among general surgery patients: Rate and risk factors. Professional Med J 2021; 28(9):1276-1281. https://doi.org/10.29309/TPMJ/2021.28.09.6076

\section{INTRODUCTION}

Post-operative surgical site infections are not only a cause of high mortality and morbidity; in addition they exert a severe economic burden as well in the developing as well as developed world. ${ }^{1}$ Patients having being exposed to invasive procedures or surgeries are at a substantially higher risk for infection. Any intact skin that is breached along with lining of the mucosa after operations offer a breeding ground for nosocomial pathogen for invading internal milieu of the tissues. ${ }^{2}$

Infections of the surgical sites also known as surgical site infection (SSI) have become an alarming problem for surgeons, being considered as an major concern for infection control postoperatively throughout the globe. ${ }^{3}$ In the western countries, annually around $2-5 \%$ of patients attain surgical site infection, amounting to a minimum of $500,000 \mathrm{SSI}$, estimated 3.7 million in excess, i.e. extra length of stay in the hospital and around $\$ 1.6$ billion in excess of hospital charges. ${ }^{4} \mathrm{~A}$ key factor in managing SSI fruitfully is to keep postoperative patients under surveillance for infection, which is pivotal since is can provide insight into patient's post-operative problems and therefore help surgeons or care-givers to undertake necessary measures and control SSI. ${ }^{5}$ In various developing populations which include Pakistan, a specific surveillance systems exist which could keep SSI and other routine nosocomial infections in check. ${ }^{6}$

In patients that have undergone surgery, SSI's are highly common nosocomial infections that account from about $16 \%$ to $38 \%$ of all infections. ${ }^{7}$ 
SSI has a debilitating effect on the patients with not only hampering their recovery and rehabilitation but also exerting a significant financial burden, especially in low-resourced setups. ${ }^{8} \mathrm{SSI}$ are regarded to be a leading reason for readmission of patients, which could cause furthers nosocomial complications such as delay in healing of wound, even revision surgery and with prolong stay at the hospital that could possibly render patients more susceptible to hospital acquired infections. ${ }^{9}$

According to the Center for Disease Control (CDC), any surveillance for SSI takes into account three wound infection classes; superficial, deep incisional or organ / space SSI. The incidences of post-operative SSI have been markedly increased since the ancient times. ${ }^{10}$ Even though they can be largely preventable, yet they tend to remain a major source for morbidity. For minimizing postoperative SSI, it is pivotal to maintain a safe and aseptic environment through control of four main infection sources, i.e. equipment, personnel, environment and the risk factors of the patient. ${ }^{11}$ Proper knowledge of certain SSI risk factors is equally important for creating a specific SSI risk stratification index, in order to develop specific strategies for limiting rate of infection. ${ }^{12}$

Since the best step in management of SSI is to prevent it, as prevention is much simpler, easier, cheaper and highly rewarding for patients for quick recovery from surgery. It is approximated that one third of infections can be easily prevented by pertaining to certain measures. ${ }^{13}$ Therefore, it is important for hospitals to have an effective infection control program in place. Any failure in lack of implementation of infection control measures or lack of awareness is confounding factors that increase SSI rate and morbidity. ${ }^{14}$ On the contrary, researches have reported that a substantial decline in SSI rates have been observed after implementation of infection control interventions. ${ }^{15}$

According to the National Research Council of USA, a system for categorizing and differentiating incisions on the basis of degree of contamination of incision was developed. It states that original classification is based upon 04 main categories: clean, clean-contaminated, contaminated and dirty. ${ }^{16}$ Nonetheless later dirty and contaminated categories were amalgamated and combined into "dirty". In hospitals, high rates of nosocomial post-surgical infections are reported with scanty effort for controlling them and more importantly, preventing them. ${ }^{17}$ The objectives of this present study were to determine and evaluate the frequency of surgical site infections in patients undergoing general surgery at a secondary care hospital.

\section{MATERIAL \& METHODS}

This retrospective cross sectional study using non-probability convenient sampling technique was conducted at the general surgery department of Naz Memorial Hospital for a period of 1 year from $15^{\text {th }}$ March 2019 to $15^{\text {th }}$ March 2020 . All surgical patients over 18 years of age admitted in surgery ward of the hospital either as elective or emergency case were included in the study while patients having any sort of wound infection, operated in any other hospital or with diabetic foot and all those patients operated for incision and drainage of an abscess were excluded from the study. All patients that were operated during the study period were followed for any wound infection development. Any patient who underwent multiple admissions or was operated more than once for complications was counted as one.

Before including patients into the study, informed consent was taken. All details collected from the patients was recorded including history, indication for surgery, type of surgery, comorbidities and all investigations done during hospital stay. Operative details included type of surgery, surgery duration and use of prophylactic anti-biotic. Wounds for infection were examined right from post-operation. SSI was determined with inflammation, redness, pain, localized heat, temperature 38 Celsius or above and septic discharge from incisional site till 30 days postoperatively, in accordance with WHO guidelines.

Management of infection was done using the standard protocol which involved repeated dressings, draining of pus if needed and use of 
broad spectrum antibiotics. Pre and post-operative length of stay at the hospital was recorded and the infected wounds were regularly inspected at reach follow up until healing was complete. Data was entered and analyzed using SPSS version 23.0. For demographic and qualitative variables, frequency and percentages were recorded and tabulated.

\section{RESULTS}

According to the results of the study, from the total of 200 patients registered for undergoing surgeries, 75 developed surgical site infection making the overall rate of surgical site infections recorded at $37.5 \% .120(60 \%)$ of the patients in the study were males while $40 \%$ were females. Among the infected patients, majority, i.e. 55\% were males.

Among the 75 infected patients, 46 (61.3\%) were operated in emergency setting while 29 (38.7\%) in elective setting Figure-I.

From 96 clean type of surgery, 20 (20.8\%) developed surgical site infection (SSI) having a non-significant p-value of 0.09 . In 52 cleancontaminated surgeries, $16(30.8 \%)$ of the patients had SSI having an insignificant difference of 0.56 . Among 24 surgeries that were contaminated type, 17 (70.8\%) were reported to have SSI with a significant difference of 0.05 while from 28 dirty type of surgeries, $22(78.6 \%)$ of patients were found to have a SSI having a significant difference of 0.03 Table-l.

From the 75 infected patients with SSI, 19 (25\%) were found to be anemic, 16 (21\%) were diabetic, $15(20 \%)$ were reported to be hypertensive, 13 (17\%) gave a positive history of smoking while 12 (16\%) were found to be obese Table-II.

\begin{tabular}{|l|c|c|c|}
\hline \multicolumn{1}{|c|}{ Type of Surgery } & $\begin{array}{c}\text { Total } \\
\text { Patients } \\
\mathbf{n = 2 0 0}\end{array}$ & $\begin{array}{c}\text { Infected } \\
\text { Patients } \\
\mathbf{n = 7 5}\end{array}$ & P-Value \\
\hline Clean & $96(48)$ & $20(20.8)$ & 0.09 \\
\hline Clean-contaminated & $52(26)$ & $16(30.8)$ & 0.56 \\
\hline Contaminated & $24(12)$ & $17(70.8)$ & 0.05 \\
\hline Dirty & $28(14)$ & $22(78.6)$ & 0.03 \\
\hline
\end{tabular}

Table-I. Surgical site infection rate with regards to different procedures.

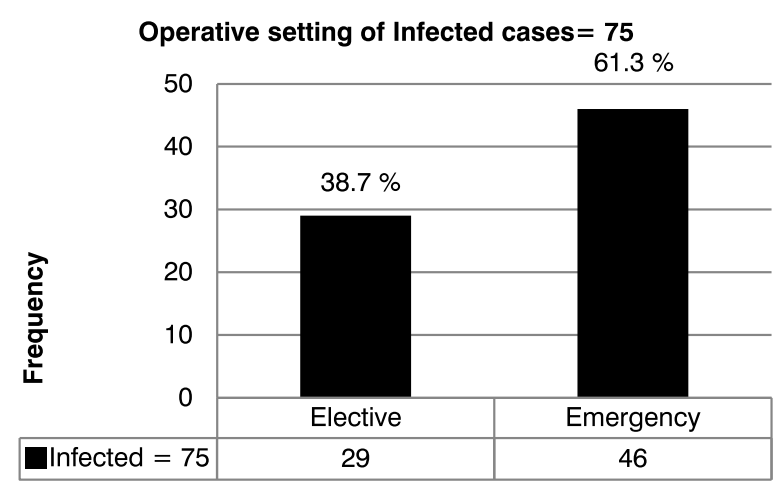

Figure-1. Operative setting of infected cases $(n=75)$.

\begin{tabular}{|l|c|}
\hline \multicolumn{1}{|c|}{ Co-morbid } & Frequency (\%) \\
\hline Anemia & $19(25.3)$ \\
\hline Diabetes & $16(21.3)$ \\
\hline Hypertension & $15(20)$ \\
\hline Smoking & $13(17.3)$ \\
\hline $\begin{array}{l}\text { Obesity } \\
\text { Table-II. Distribution of co-morbidities in infected } \\
\text { patients }\end{array}$ \\
\hline \multicolumn{2}{|c|}{$\mathbf{n = 7 5 ) .}$} \\
\hline
\end{tabular}

\section{DISCUSSION}

The rate of surgical site infection (SSI) reported in our study was significantly higher than reported in other studies. Complications in surgical procedure include $\mathrm{SSI}$ which is one of the most common forms of nosocomial infections. Therefore it is essential that surveillance be done for controlling and preventing SSI. Other studies such as one done at a tertiary care center of the same city where this study was done, i.e. Karachi reported an overall rate of SSI of $11 \%{ }^{18}$ A Kashmir study reported rate of SSI at $11.3 \% .^{19}$ Another study one in Iran reported an infection rate of $17.4 \% .^{20}$ The incidence rates recorded in researches done in the west have been extremely low when compared with the incidence rates reported in eastern studies. Researches done in USA and other European countries have observed SSI rates at $2.6 \%$ and $2.5 \%$ respectively. ${ }^{21,22}$ Similarly, studies done in Philippine, Nepal and Brazil reported incidence rates at $7.8 \%, 7.3 \%$ and $5.1 \%$ respectively. ${ }^{23-25} \mathrm{~A}$ study in Jamshoro, Pakistan recorded SSI rates of $13 \% .^{18}$ Hospitals having inappropriate and ineffective infection control system, poor practice and indiscriminate 
usage of antibiotics without considering proper guidelines tend to reported higher frequencies of complications. On top of this, another important factor is characteristics of the patients where majority of the patients visiting or being operated at secondary care low-budgeted hospitals belong to lower socio-economic status having a immune system which is compromised and with unhygienic practices, making a breeding ground for infection. ${ }^{26}$

Yet another cause of high SSI rates in our population might be because of overcrowding where high turnover of patients lead to higher work load and compromised patient care. ${ }^{27}$ Moreover, high SSI rates are also observed when moving from clean to dirty surgical procedures that are in concordance with other researches as well; however even then such class specific rates seen in our study are higher in comparison to NNIS (National Nosocomial Infection Surveillance) standards. ${ }^{28}$

Other studies have reported no relationship between developments of SSI against the gender of patients. SSI rate analysis in respect of age has shown slightly higher rates of SSI with increasing age; however most studies have reported an insignificant difference with regards to SSI development and age. ${ }^{29}$ Nonetheless, the usual age above which a higher SSI rates have been reported is 40 years. The probable reason behind this increase could be partially because of greater likelihood of chronic illnesses and reduced or compromised immunity with delay in healing in older individuals. ${ }^{20}$ Similar to our study in which emergency surgeries reported higher frequency of SSI as compared with elective surgeries, other studies have also recorded a higher incidence of SSI in patients that underwent emergency procedures when compared with elective surgeries. This shows that even an improper or lack of planning and preparation prior to a surgical procedure is also a vital aspect of postoperative patient's care. ${ }^{21}$

A study reported that health care professionals who did not perform post-discharge surveillance for SSI on patients were found to have a 13-61
$\%$ higher chance of infection which was only apparent after being discharged from the hospital. Therefore it is also important to observe the omission of post-discharge infection which could falsely report lower rates of SSI. In addition, dirtycontaminated and dirty surgeries are highest to report frequencies of SSI. In our study, population was small where sub-population groups made for example on infection rates according to type of surgery, etc. Therefore conclusions drawn from such conditions may be of limited value. ${ }^{30}$

Follow up time period in various studies as well as ours was 04 weeks after surgery. Additionally those patients which could not come for follow up were telephonically followed. Non-quantifiable risk factors for SSI include duration of surgery, prophylaxis of antibiotic as well as preparation of skin has been denoted to be vital in other researches, however these factors are difficult to retrospectively quantify and therefore were not included or part of this study. In addition to these limitations, this study was not immune from selection and observer bias and the fact that the study was conducted in a single center with limited sample size.

\section{CONCLUSION}

According to the results of the study, higher proportion of surgical site infection was observed in patients undergoing contaminated and dirty type of surgeries. Most patients with SSI were operated in emergency setting and anemia and diabetes were the most common risk factor reported in the infected patients.

\section{Copyright $@ 24$ Nov, 2020.}

\section{REFERENCES}

1. De Lissovoy G, Fraeman K, Hutchins V, Murphy D, Song $D$, Vaughn BB. Surgical site infection: Incidence and impact on hospital utilization and treatment costs. American journal of infection control. 2009 Jun 1; 37(5):387-97.

2. Berríos-Torres SI, Umscheid CA, Bratzler DW, Leas B, Stone EC, Kelz RR, et al. Centers for disease control and prevention guideline for the prevention of surgical site infection, 2017. JAMA surgery. 2017 Aug $1 ; 152(8): 784-91$ 
3. Mu Y, Edwards JR, Horan TC, Berrios-Torres SI, Fridkin SK. Improving risk-adjusted measures of surgical site infection for the National Healthcare Safely Network. Infection Control \& Hospital Epidemiology. 2011 Oct; 32(10):970-86.

4. Hawn MT, Vick CC, Richman J, Holman W, Deierhoi RJ, Graham LA, et al. Surgical site infection prevention: Time to move beyond the surgical care improvement program. Annals of surgery. 2011 Sep 1; 254(3):494501.

5. Ban KA, Minei JP, Laronga C, Harbrecht BG, Jensen $\mathrm{EH}$, Fry DE, et al. American College of Surgeons and Surgical Infection Society: Surgical site infection guidelines, 2016 update. Journal of the American College of Surgeons. 2017 Jan 1; 224(1):59-74.

6. Malik AZ. Surgical site infections after elective surgery in Pakistan: Surgipak Study. Journal of Rawalpindi Medical College. 2015 Dec 30; 19(3):20914.

7. Anthony T, Murray BW, Sum-Ping JT, Lenkovsky F, Vornik VD, Parker BJ, et al. Evaluating an evidencebased bundle for preventing surgical site infection: A randomized trial. Archives of Surgery. 2011 Mar 1; 146(3):263-9.

8. Rosenberger LH, Politano AD, Sawyer RG. The surgical care improvement project and prevention of postoperative infection, including surgical site infection. Surgical infections. 2011 Jun 1; 12(3):163-8.

9. Allegranzi B, Bischoff P, de Jonge S, Kubilay NZ, Zayed $B$, Gomes SM, et al. New WHO recommendations on preoperative measures for surgical site infection prevention: An evidence-based global perspective. The Lancet Infectious Diseases. 2016 Dec 1; 16(12):e276-87.

10. Harrop JS, Styliaras JC, Ooi YC, Radcliff KE, Vaccaro AR, Wu C. Contributing factors to surgical site infections. JAAOS-Journal of the American Academy of Orthopaedic Surgeons. 2012 Feb 1; 20(2):94-101.

11. Korol E, Johnston K, Waser N, Sifakis F, Jafri HS, Lo M, et al. A systematic review of risk factors associated with surgical site infections among surgical patients. PloS one. 2013; 8(12):e83743-52.

12. Malone DL, Genuit T, Tracy JK, Gannon C, Napolitano LM. Surgical site infections: Reanalysis of risk factors. Journal of Surgical Research. 2002 Mar 1; 103(1):89-95.
13. Allegranzi B, Zayed B, Bischoff $P$, Kubilay NZ, de Jonge $S$, de Vries F, et al. New WHO recommendations on intraoperative and postoperative measures for surgical site infection prevention: An evidencebased global perspective. The Lancet Infectious Diseases. 2016 Dec 1; 16(12):e288-303.

14. Berenguer CM, Ochsner Jr MG, Lord SA, Senkowski CK. Improving surgical site infections: Using national surgical quality improvement program data to institute surgical care improvement project protocols in improving surgical outcomes. Journal of the American College of Surgeons. 2010 May 1; 210(5):737-41.

15. Awad SS. Adherence to surgical care improvement project measures and post-operative surgical site infections. Surgical infections. 2012 Aug 1; 13(4):2347.

16. Fan CJ, Pawlik TM, Daniels T, Vernon N, Banks K, Westby $P$, et al. Association of safety culture with surgical site infection outcomes. Journal of the American College of Surgeons. 2016 Feb 1; 222(2):122-8.

17. Marković-Denić L. Studies of prevalence in surveillance of hospital-acquired infections. Medicinski pregled. 2011; 64(7-8):353-6.

18. Sangrasi AK, Leghari AA, Memon A, Talpur AK, Qureshi GA, Memon JM. Surgical site infection rate and associated risk factors in elective general surgery at a public sector medical university in Pakistan. International wound journal. 2008 Mar; 5(1):74-8.

19. Mustafa A, Bukhari IA, Kakru DK, Tabish SA, Qadri GJ. Incidence of nosocomial wound infection in postoperative patients at a teaching hospital In Kashmir. Jk practitioner. 2004; 11(1):38-40.

20. Razavi SM, Ibrahimpoor M, Kashani AS, Jafarian A. Abdominal surgical site infections: Incidence and risk factors at an Iranian teaching hospital. BMC surgery. 2005 Dec 1; 5(1):2-7.

21. Gaynes RP, Culver DH, Horan TC, Edwards JR, Richards C, Tolson JS, National nosocomial infections surveillance system. Surgical site infection (SSI) rates in the United States, 1992-1998: The National Nosocomial Infections Surveillance System basic SSI risk index. Clinical Infectious Diseases. 2001 Sep 1; 33(2):69-77.

22. Leaper DJ, Van Goor H, Reilly J, Petrosillo N, Geiss HK, Torres AJ, et al. Surgical site infection-a European perspective of incidence and economic burden. International wound journal. 2004 Dec; 1(4):247-73. 
23. Siguan SS, Ang BS, Pala IM, Baclig RM. Aerobic surgical infection: A surveillance on microbiological etiology and antimicrobial sensitivity pattern of commonly used antibiotics. Phil J Microbiol Infect Dis. 1990; 19(1):27-33.

24. Giri BR, Pant HP, Shankar PR, Sreeramareddy CT, Sen PK. Surgical site infection and antibiotics use pattern in a tertiary care hospital in Nepal. JPMA. The Journal of the Pakistan Medical Association. 2008 Mar; 58(3):148-51.

25. Medeiros AC, Aires-Neto T, Azevedo GD, Vilar MJ, Pinheiro LA, Brandão-Neto J. Surgical site infection in a university hospital in northeast Brazil. Brazilian Journal of Infectious Diseases. 2005 Aug; 9(4):310-4.

26. Afifi IK, Labah EA, Ayad KM. Surgical site infections after elective general surgery in Tanta University Hospital: Rate, risk factors and microbiological profile. Egyptian J Med Microbiol. 2009 Apr; 18(2):6172.
27. Virtanen M, Terho K, Oksanen T, Kurvinen T, Pentti J, Routamaa M, et al. Patients with infectious diseases, overcrowding, and health in hospital staff. Archives of internal medicine. $2011 \mathrm{Jul} 25 ; 171(14)$ :1296-8.

28. Staszewicz W, Eisenring MC, Bettschart V, Harbarth S, Troillet $\mathrm{N}$. Thirteen years of surgical site infection surveillance in Swiss hospitals. Journal of Hospital Infection. 2014 Sep 1; 88(1):40-7.

29. Mu Y, Edwards JR, Horan TC, Berrios-Torres SI, Fridkin SK. Improving risk-adjusted measures of surgical site infection for the National Healthcare Safely Network. Infection Control \& Hospital Epidemiology. 2011 Oct; 32(10):970-86.

30. Anjum N, Ren J, Wang G, Li G, Wu X, Dong H, et al. A randomized control trial of preoperative oral antibiotics as adjunct therapy to systemic antibiotics for preventing surgical site infection in clean contaminated, contaminated, and dirty type of colorectal surgeries. Diseases of the Colon \& Rectum. 2017 Dec 1; 60(12):1291-8.

\begin{tabular}{|c|c|c|c|}
\hline \multicolumn{4}{|c|}{ AUTHORSHIP AND CONTRIBUTION DECLARATION } \\
\hline Sr. \# & Author(s) Full Name & Contribution to the paper & Author(s) Signature \\
\hline 1 & Shahid Nazir Memon & $\begin{array}{l}\text { Conception and design of } \\
\text { study. }\end{array}$ & Whahid nazir \\
\hline 2 & $\begin{array}{l}\text { Shehzada Ameer Ahmed } \\
\text { Babar }\end{array}$ & $\begin{array}{l}\text { Conception and design of } \\
\text { study. }\end{array}$ & Shehzada CBabar \\
\hline 3 & Sarwat Sultana & Final approval for version. & Sarwat \\
\hline 4 & Sulhera Khan & Final approval for version. & sulhera \\
\hline 5 & Amir Hussain Khan & $\begin{array}{l}\text { Data analysis write up and } \\
\text { proof reading. }\end{array}$ & Amirkhan \\
\hline 6 & Anas Bin Tariq & $\begin{array}{l}\text { Data analysis write up and } \\
\text { proof reading. }\end{array}$ & Ahas taking \\
\hline
\end{tabular}

